\title{
Effect of Bladderbox Alarms During Venoarterial Extracorporeal Membrane Oxygenation on Cerebral Oxygenation and Hemodynamics in Lambs
}

\author{
AMERIK C. De MOL, LUELLA C. GERRITS, ARNO F. J. van HEIJST, JAN MENSSEN, FRANS H. J. M. van DER STAAK, \\ AND KIAN D. LIEM
}

Department of Pediatrics [A.C.M., L.C.G., A.F.J.H., K.D.L.], Laboratory of Clinical Physics [J.M.], and Department of Pediatric Surgery [F.H.J.M.S.], Radboud University Nijmegen Medical Centre, Nijmegen 6500 HB, The Netherlands; Department of Pediatrics [A.C.M.], Albert Schweitzer Hospital, Dordrecht 3318 AT, The Netherlands

\begin{abstract}
To determine the effects of bladderbox alarms during venoarterial extracorporeal membrane oxygenation (va-ECMO) on cerebral oxygenation and hemodynamics, six lambs were prospectively treated with va-ECMO and bladderbox alarms were simulated. Changes in concentrations of oxyhemoglobin $\left(\Delta \mathrm{cO}_{2} \mathrm{Hb}\right)$, deoxyhemoglobin $(\Delta \mathrm{cHHb})$, and total $\mathrm{Hb}(\Delta \mathrm{ctHb})$ were measured using near infrared spectrophotometry. Fluctuations in $\mathrm{Hb}$ oxygenation index $(\Delta \mathrm{HbD})$ and cerebral blood volume $(\Delta \mathrm{CBV})$ were calculated. Heart rate (HR), mean arterial pressure (MAP), blood flow in the left carotid artery (Qcar), and central venous pressure (CVP) were registered. Bladderbox alarms were simulated by increasing the ECMO flow or partially clamping the venous cannula and resolved by decreasing the ECMO flow, unclamping the cannula, or intravascular volume administration. $\mathrm{CBV}, \mathrm{HbD}, \mathrm{MAP}$, and Qcar decreased significantly during bladderbox alarms, whereas HR and CVP increased. After the bladderbox alarms, CBV and HbD increased significantly to values above baseline. For $\mathrm{HbD}$, this increase was higher during intravascular volume administration. MAP, Qcar, and CVP recovered to preexperiment values but increased further with volume administration. HR was increased at the end of our measurements. We conclude that Bladderbox alarms during va-ECMO treatment result in significant fluctuations in cerebral oxygenation and hemodynamics, a possible risk factor for intracranial lesions. (Pediatr Res 66: 688-692, 2009)
\end{abstract}

$\mathrm{E}$ xtracorporeal membrane oxygenation (ECMO) has become a rescue therapy for neonates with severe, but potentially reversible, respiratory failure when maximal conventional therapy has failed. Without ECMO, there is a high mortality rate $(1,2)$. Since the first newborn was successfully treated with venoarterial extracorporeal membrane oxygenation (va-ECMO) by Bartlett et al. in 1976 (3), more than 22,000 neonates have been treated with ECMO, of which 15,000 with va-ECMO, with an overall survival rate of $80 \%$ (4). Although ECMO has increased survival, the occurrence of hemorrhagic and ischemic cerebral lesions resulting in future neurologic and neurodevelopmental dysfunction are of major concern $(5,6)$. Imaging studies revealed hemorrhagic or ischemic intracranial abnormalities in 10 up to even $52 \%$ of the

Received April 17, 2009; accepted August 17, 2009.

Correspondence: Amerik C. de Mol, M.D., Department of Pediatrics, Radboud University Nijmegen Medical Centre, P.O. Box 9101, 6500 HB Nijmegen, The Netherlands; e-mail: a.c.demol@cukz.umcn.nl patients (7-9). These complications justify a continuous search for factors related to intracranial hemorrhage and ischemia and treatment strategies aimed to improve outcome.

Part of the va-ECMO system is a bladderbox, which is situated between the venous cannula and the rollerpump of the extracorporeal system. The bladderbox controls venous drainage of blood from the right atrium of the patient. If the venous drainage becomes inadequate to maintain the established flow of the ECMO system, the bladderbox will give an alarm, slow down the pump, and finally cause an acute interruption of the rollerpump resulting in interruption of blood flow to the patient. If other causes of inadequate venous drainage from the right atrium and consecutive bladderbox alarms, like disturbed position of the cannula, are ruled out, intravascular volume administration is often given to restore the circulation through the ECMO system and the patient. Recently, our group first showed a statistically significant relation between the total number and volume of intravascular volume administration and the occurrence of intracranial hemorrhage (ICH) during va-ECMO treatment (10). We hypothesize that this relation may be explained by fluctuations in cerebral oxygenation and hemodynamics caused by either the bladderbox alarms with a consecutive interruption of the ECMO blood flow to the patient or by intravascular volume administration itself. Both might be a contributing risk factor for intracranial hemorrhage and ischemia. The aim of this study is to describe possible fluctuations in cerebral oxygenation and hemodynamics, as measured by near infrared spectrophotometry (NIRS), caused by simulated bladderbox alarms during va-ECMO in lambs.

\footnotetext{
Abbreviations: AR, cerebral autoregulation; $\triangle \mathbf{C B V}$, changes in cerebral blood volume; $\mathbf{c H b}$, concentration of hemoglobin in circulating blood; $\mathbf{\Delta c H H b}$, changes in concentration deoxyhemoglobin; $\mathbf{\Delta} \mathbf{c t H b}$, changes in concentration of total hemoglobin; $\Delta \mathbf{c} \mathbf{O}_{\mathbf{2}} \mathbf{H b}$, changes in concentration of oxyhemoglobin; CVP, central venous pressure; $\mathbf{A H b D}$, changes in hemoglobin oxygenation index; HR, heart rate; ICH, intracranial hemorrhage; MAP, mean arterial pressure; NIRS, near infrared spectrophotometry; Qcar, blood flow in the left carotic artery; $\mathbf{S a O}_{\mathbf{2}}$, arterial oxygen saturation; va-ECMO, venoarterial extracorporeal membrane oxygenation
} 


\section{METHODS}

Study population and ECMO. In a prospective interventional setting, six healthy lambs were studied for changes in cerebral oxygenation and hemodynamics caused by bladderbox alarms during va-ECMO. The lambs were obtained from local farmers, and the Ethical Committee on Animal Research of the Radboud University of Nijmegen approved the study. The care and handling of the animals were in accordance with the guidelines issued by the National Institutes of Health. Experimental settings were mainly based on earlier research in our group (11). General anesthesia was induced by i.v. administration of midazolam $0.2 \mathrm{mg} \cdot \mathrm{kg}^{-1}$, ketamine $15 \mathrm{mg} \cdot \mathrm{kg}^{-1}$, atropine $0.01 \mathrm{mg} \cdot \mathrm{kg}^{-1}$, and pentobarbital $20 \mathrm{mg} \cdot \mathrm{kg}^{-1}$. Muscle relaxation was obtained with $0.02 \mathrm{mg} \cdot \mathrm{kg}^{-1}$ pancuronium. After endotracheal intubation, mechanical ventilation was started using a Babylog 8000 (Dräger, Lübeck, Germany) to maintain normal blood gas values (pH, 7.30-7.40; $\mathrm{PaO}_{2}, 10-15$ $\left.\mathrm{kPa} ; \mathrm{PaCO}_{2}, 4.5-5.5 \mathrm{kPa}\right)$. During mechanical ventilation, anesthesia was maintained by infusion of midazolam $\left(0.2 \mathrm{mg} \cdot \mathrm{kg}^{-1} \cdot \mathrm{h}^{-1}\right)$, ketamine $(10$ $\left.\mathrm{mg} \cdot \mathrm{kg}^{-1} \cdot \mathrm{h} \cdot-1\right)$, sufentanyl $\left(20 \mu \mathrm{g} \cdot \mathrm{kg}^{-1} \cdot \mathrm{h}^{-1}\right)$, and pancuronium $(0.02$ $\mathrm{mg} \cdot \mathrm{kg}^{-1} \cdot \mathrm{h}^{-1}$ ). Heart rate (HR) was monitored by needle electrodes on the chest wall. Central temperature was measured with a rectal probe and maintained between 38.5 and $39.5^{\circ} \mathrm{C}$. A catheter was placed in the aorta through the right femoral artery for continuous measurement of mean arterial blood pressure (MAP). The right femoral vein was used to place a $7.5-\mathrm{Fr}$ catheter into the inferior caval vein to create a venous access for medication and measurement of central venous pressure (CVP). Both MAP and CVP were represented on one monitor (HP 68S, Hewlett Packard, Boeblingen, Germany). Blood flow in the left common carotic artery (Qcar) was measured using an ultrasonic flowmeter (Transonic Systems Inc, NY, NY). Finally, arterial oxygen saturation $\left(\mathrm{SaO}_{2}\right)$ and end-tidal $\mathrm{CO}_{2}$ were continuously registered.

Before venoarterial cannulation, the ECMO circuit was primed with full fresh sheep blood. The right common carotid artery was cannulated with an arterial catheter (8-12 Fr) and the right internal jugular vein with a venous catheter 10-12 Fr (both Biomedicus, Medtronics Bio-Medicus, Eden Prairie, $\mathrm{MN})$. Thereafter, va-ECMO was initiated. During the cannulation procedure, a loading dose of heparin was administered $(150 \mathrm{IU} / \mathrm{kg})$ followed by continuous i.v. infusion of heparin $\left(100-200 \mathrm{IU} \cdot \mathrm{kg}^{-1} \cdot \mathrm{h}^{-1}\right)$ to maintain the activated clotting time between 200 and $250 \mathrm{~s}$ (Hemochron, Edison, NJ).

The ECMO circuit itself consisted of a custom packed 1/4-inch flexible polyvinylchloride tubing (Baxter, Uden, The Netherlands), with a silicone reservoir, the bladderbox (Seabrook Medical Systems, Inc, Cincinnati, OH), a hollow fiber membrane oxygenator with integrated heat-exchanger (Medos Hilite 2400LT, Medos, Stolberg Germany), and a rollerpump (Jostra RPM 20-320, Lung, Sweden). An ultrasonic flow meter (Transonic Systems, Ithaca, NY) was placed on the venous site of the ECMO system continuously measuring actual flow in the circuit. The aimed flow rate of the ECMO pump was $100-150 \mathrm{~mL} \cdot \mathrm{kg}^{-1} \cdot \mathrm{min}^{-1}$

NIRS. Cerebral oxygenation and hemodynamics were studied with NIRS. The NIRS equipment (OXYMON) used was developed by the instrumentation department and the department of physiology of the Radboud University Nijmegen Medical Centre, The Netherlands (12). The technique is based on the spectrophotometric measurement of changes in the absorption properties of $\mathrm{Hb}$ in the near infrared region, depending on its oxygenation state, first described by Jöbsis in 1977 (13). The NIRS procedure used in our ECMO center has been described to more extend in earlier studies of our research group $(14,15)$. From an optode, placed frontal in the midline of the skull, three wavelengths of near infrared light $(905,850$, and $767 \mathrm{~nm})$ were transmitted through the head and received by two other optodes placed both on the left and right parietotemporal region of the skull, to evaluate the oxygenation and hemodynamics in each hemisphere separately. Concentration changes of oxyhemoglobin $\left(\Delta \mathrm{cO}_{2} \mathrm{Hb}\right)$ and deoxyhemoglobin $(\Delta \mathrm{cHHb})$ were calculated from changes in light absorption using the modified Lambert-Beer law. We used the Keele absorption matrix and a constant path length multiplier factor of 4.27 times the distance between both optodes (16-18). Using a value of $1.05 \mathrm{~g} \cdot \mathrm{mL}^{-1}$ for brain specific mass, concentration changes are expressed in $\mu \mathrm{mol} \cdot 100 \cdot \mathrm{g}^{-1}$ (19). $\Delta \mathrm{cO}_{2} \mathrm{Hb}$ and $\Delta \mathrm{cHHb}$ reflect changes in cerebral oxygen supply, if oxygen consumption remains constant. Differences between $\Delta \mathrm{cO}_{2} \mathrm{Hb}$ and $\Delta \mathrm{cHHb}$ were calculated and indicated as changes in the $\mathrm{Hb}$ oxygenation index $\left(\Delta \mathrm{HbD}\right.$, where $\Delta \mathrm{HbD}=\Delta \mathrm{cO}_{2} \mathrm{Hb}-\Delta \mathrm{cHHb}$ in $\left.\mu \mathrm{mol} \cdot 100 \cdot \mathrm{g}^{-1}\right)$. Concentration changes in total $\mathrm{Hb}(\Delta \mathrm{ctHb})$ were calculated as the sum of $\Delta \mathrm{cO}_{2} \mathrm{Hb}$ and $\Delta \mathrm{cHHb}\left(\Delta \mathrm{ctHb}=\Delta \mathrm{cO}_{2} \mathrm{Hb}+\Delta \mathrm{cHHb}\right) . \Delta \mathrm{HbD}$ represents changes in cerebral blood flow (20), whereas $\Delta$ ctHb reflects changes in cerebral blood volume $(\Delta \mathrm{CBV})$, which are calculated from the formula: $\Delta \mathrm{CBV}=4 \times \Delta \mathrm{ctHb} / 0.69 \times \mathrm{cHb}$, expressed in $\mathrm{mL} \cdot 100 \cdot \mathrm{g}^{-1}$. In this formula, $\mathrm{cHb}$ is the $\mathrm{Hb}$ concentration in circulating blood ( $\mathrm{mmol} / \mathrm{L}), 0.69$ is the cerebral-arterial hematocrit ratio, and 4 is a correction factor. Also, because ctHb is calculated from changes in light absorption using an extinc- tion coefficient based on the tetrahaeme molecule, whereas $\mathrm{cHb}$ determination is based on the monohaeme molecule (21).

Experimental procedures. After the initiation of va-ECMO, we waited for a stable NIRS signal. Once this was established, bladderbox alarms were simulated. During the first experiment (experiment A), the ECMO flow rate of the rollerpump was increased stepwise with $10 \mathrm{~mL} \cdot \mathrm{kg}^{-1} \cdot \mathrm{min}^{-1}$ until bladderbox alarms occurred. After $10 \mathrm{~s}$, the ECMO flow rate was decreased to the preexperiment value, and the bladderbox alarms were thereby resolved. Experiment A was repeated three times in each lamb with a minimal time interval of 2 min to obtain a stable NIRS signal before each experiment for at least $30 \mathrm{~s}$.

During the second experiment (experiment B), the venous cannula of the ECMO circuit was partially occluded by a nonocclusive clamp that was developed for this experiment. Bladderbox alarms occurred as result of insufficient venous drainage and after $10 \mathrm{~s}$, the clamp was removed to restore the preexperiment ECMO flow and resolve the bladderbox alarms. Again, experiment $\mathrm{B}$ was repeated three times in each lamb with a minimal time interval of $2 \mathrm{~min}$.

During the third experiment (experiment C), bladderbox alarms were simulated similar to experiment A. However, after $10 \mathrm{~s}$, bladderbox alarms were resolved by starting intravascular volume administration with $50 \mathrm{~mL}$ of normal saline. To avoid an overload of intravascular volume administration, experiment $\mathrm{C}$ was repeated two times in each lamb, with a time interval long enough to obtain at least a $30 \mathrm{~s}$ stable NIRS signal.

Arterial blood samples were obtained before and after each experiment to check for changes in $\mathrm{pH}, \mathrm{PaO}_{2}, \mathrm{PaCO}_{2}$, and $\mathrm{cHb}$ values.

Data analysis. All physiologic parameters were registered by a data acquisition system (Poly, Inspector Research System, Amsterdam, The Netherlands) with a sampling frequency of $1 \mathrm{~Hz}$ and synchronized with the NIRS data. Baseline values (mean $\pm \mathrm{SD}$ ) of $\mathrm{cO}_{2} \mathrm{Hb}, \mathrm{cHHb}, \mathrm{ctHb}$, and physiologic parameters were determined during a $15-\mathrm{s}$ period during the stable NIRS signal before $(t=0)$ each single experiments (A, B, and C). Maximal changes in $\mathrm{cO}_{2} \mathrm{Hb}, \mathrm{cHHb}$, ctHb, and physiologic parameters were searched by a computer analysis during $(t=1)$ and after resolving $(t=2)$ the bladderbox alarms as mean values during a 3 -s period. Because of the continuous registration, related changes in physiologic data could be described during changes of the NIRS signals. Changes in $\mathrm{HbD}$ and $\mathrm{CBV}$ were calculated by using the formulas mentioned earlier. All changes were described separately for the left and right hemisphere of the brain. Therefore, $\Delta \mathrm{HbD}$ is expressed as $\triangle \mathrm{HbD}_{\text {right }}$ and $\triangle \mathrm{HbD}_{\text {left }}$, while $\triangle \mathrm{CBV}$ is expressed as $\triangle \mathrm{CBV}_{\text {right }}$ and $\Delta \mathrm{CBV}_{\text {left }}$. Statistical analysis was performed for maximal changes at $t=1$ and $t=2$ compared with the baseline values by using Wilcoxon signed ranks tests, and $p$ values $<0.05$ were considered to be statistically significant.

\section{RESULTS}

All the three experiments A, B, and C were successfully performed in six lambs, weight (mean $\pm \mathrm{SD}) 5.2 \pm 1.1 \mathrm{~kg}$. The flow rate of the ECMO pump aimed for (100-150 $\mathrm{mL} \cdot \mathrm{kg}^{-1} \cdot \mathrm{min}^{-1}$ ) was reached in five lambs. In one lamb, maximal flow rate of the ECMO pump was $90 \mathrm{~mL} \cdot \mathrm{kg}^{-1} \cdot \mathrm{min}^{-1}$. As measured by arterial blood gas samples, all the lambs had blood gas values within the normal range before and after each experiment. For each experiment, $\mathrm{cHb}$ could be determined and used for calculations of $\triangle \mathrm{CBV}$. An overview of mean changes in important physiologic parameters, $\mathrm{HbD}$ and $\mathrm{CBV}$, is given in Table 1, while Figure 1 shows the typical pattern of $\mathrm{cO}_{2} \mathrm{Hb}, \mathrm{cHHb}, \mathrm{HbD}$, and $\mathrm{CBV}$ during and after bladderbox alarms in one lamb. Baseline $\mathrm{HbD}$ and CBV values, calculated during a 15 -s period showed a baseline variability with a mean $\mathrm{SD}$ of $0.03 \pm 0.01 \mu \mathrm{mol} \cdot 100 \cdot \mathrm{g}^{-1}$ and $0.02 \pm 0.01$ $\mathrm{mL} \cdot 100 \cdot \mathrm{g}^{-1}$, respectively. Significant changes in $\mathrm{SaO}_{2}$ and end-tidal $\mathrm{CO}_{2}$ were not observed.

Bladderbox alarms caused a significant and acute decrease in $\mathrm{O}_{2} \mathrm{Hb}$ and increase in $\mathrm{HHb}$. After the acute decrease, there was a slight increase in $\mathrm{O}_{2} \mathrm{Hb}$ during the period of bladderbox alarms, followed by an acute increase to values above baseline values when bladderbox alarms were resolved. After the acute increase, $\mathrm{HHb}$ did show a further very slight increase during 
Table 1. Changes in hemoglobin oxygenation index $(H b D)$, cerebral blood volume $(C B V)$, mean arterial pressure $(M A P)$, blood flow in the left carotic artery (Qcar), heart rate $(H R)$, and central venous pressure $(C V P)$ during and after bladderbox alarms, compared with baseline values

\begin{tabular}{|c|c|c|c|}
\hline Exp & $\begin{array}{c}\text { Baseline } \\
(t=0)\end{array}$ & $\begin{array}{c}\begin{array}{c}\text { Bladderbox } \\
\text { alarms }\end{array} \\
(t=1) \text { change }\end{array}$ & $\begin{array}{l}\text { After recovery } \\
\quad(t=2) \\
\text { change }\end{array}$ \\
\hline \multicolumn{4}{|l|}{ A } \\
\hline $\begin{array}{l}\mathrm{HbD}_{\text {right }} \\
\quad\left(\mu \mathrm{mol} \cdot 100 \cdot \mathrm{g}^{-1}\right)\end{array}$ & NA & $-0.20 \pm 0.10^{*}$ & $0.11 \pm 0.12 \dagger$ \\
\hline $\begin{array}{l}\mathrm{HbD}_{\text {left }} \\
\quad\left(\mu \mathrm{mol} \cdot 100 \cdot \mathrm{g}^{-1}\right)\end{array}$ & NA & $-0.20 \pm 0.10^{*}$ & $0.10 \pm 0.11 \dagger$ \\
\hline $\mathrm{CBV}_{\text {right }}\left(\mathrm{mL} \cdot 100 \cdot \mathrm{g}^{-1}\right)$ & NA & $-0.11 \pm 0.05^{*}$ & $0.13 \pm 0.11 *$ \\
\hline $\begin{array}{l}\mathrm{CBV}_{\text {left }} \\
\quad\left(\mathrm{mL} \cdot 100 \cdot \mathrm{g}^{-1}\right)\end{array}$ & NA & $-0.11 \pm 0.05^{*}$ & $0.12 \pm 0.08^{*}$ \\
\hline MAP $(\mathrm{mm} \mathrm{Hg})$ & $65 \pm 11$ & $-9.8 \pm 5.8^{*}$ & $-0.4 \pm 1.2$ \\
\hline Qcar $\left(\mathrm{mL} \cdot \mathrm{min}^{-1}\right)$ & $119 \pm 63$ & $-19.2 \pm 13.6^{*}$ & $0.7 \pm 3.9$ \\
\hline $\mathrm{HR}$ (beats $\cdot \min ^{-1}$ ) & $147 \pm 36$ & $5 \pm 4 *$ & $7 \pm 6^{*}$ \\
\hline $\mathrm{CVP}(\mathrm{mm} \mathrm{Hg})$ & $5.2 \pm 2.7$ & $0.7 \pm 0.9 \dagger$ & $-0.3 \pm 0.5$ \\
\hline \multicolumn{4}{|l|}{ B } \\
\hline $\begin{array}{l}\mathrm{HbD}_{\text {right }} \\
\quad\left(\mu \mathrm{mol} \cdot 100 \cdot \mathrm{g}^{-1}\right)\end{array}$ & NA & $-0.17 \pm 0.05^{*}$ & $0.14 \pm 0.07 *$ \\
\hline $\mathrm{HbD}_{\text {left }}\left(\mu \mathrm{mol} \cdot 100 \cdot \mathrm{g}^{-1}\right)$ & NA & $-0.13 \pm 0.05^{*}$ & $0.11 \pm 0.05^{*}$ \\
\hline $\mathrm{CBV}_{\text {right }}\left(\mathrm{mL} \cdot 100 \cdot \mathrm{g}^{-1}\right)$ & NA & $-0.11 \pm 0.05^{*}$ & $0.10 \pm 0.05^{*}$ \\
\hline $\mathrm{CBV}_{\text {left }}\left(\mathrm{mL} \cdot 100 \cdot \mathrm{g}^{-1}\right)$ & NA & $-0.09 \pm 0.04 *$ & $0.08 \pm 0.06^{*}$ \\
\hline MAP (mm Hg) & $62 \pm 10$ & $-9.3 \pm 1.7 *$ & $0.2 \pm 1.6$ \\
\hline Qcar $\left(\mathrm{mL} \cdot \mathrm{min}^{-1}\right)$ & $102 \pm 58$ & $-12.1 \pm 9.0^{*}$ & $1.7 \pm 3.7$ \\
\hline $\mathrm{HR}$ (beats $\cdot \min ^{-1}$ ) & $158 \pm 42$ & $3 \pm 3 \dagger$ & $4 \pm 3 *$ \\
\hline $\mathrm{CVP}(\mathrm{mm} \mathrm{Hg})$ & $5 . .8 \pm 2.9$ & $0.9 \pm 0.6 \dagger$ & $-0.6 \pm 0.4 \dagger$ \\
\hline \multicolumn{4}{|l|}{$\mathrm{C}$} \\
\hline $\begin{array}{l}\mathrm{HbD}_{\text {right }} \\
\quad\left(\mu \mathrm{mol} \cdot 100 \cdot \mathrm{g}^{-1}\right)\end{array}$ & NA & $-0.21 \pm 0.11^{*}$ & $0.33 \pm 0.17 *$ \\
\hline $\begin{array}{l}\mathrm{HbD}_{\text {left }} \\
\quad\left(\mu \mathrm{mol} \cdot 100 \cdot \mathrm{g}^{-1}\right)\end{array}$ & NA & $-0.21 \pm 0.15^{*}$ & $0.33 \pm 0.24 *$ \\
\hline $\operatorname{MAP}(\mathrm{mm} \cdot \mathrm{Hg})$ & $67 \pm 15$ & $-8.3 \pm 3.5 \dagger$ & $13.6 \pm 5.5 \dagger$ \\
\hline Qcar $\left(\mathrm{mL} \cdot \mathrm{min}^{-1}\right)$ & $102 \pm 48$ & $-11.2 \pm 8.5 \dagger$ & $34.5 \pm 23.2 \dagger$ \\
\hline $\mathrm{HR}$ (beats $\cdot \min ^{-1}$ ) & $155 \pm 35$ & $3 \pm 4+$ & $3 \pm 3 \ddagger$ \\
\hline CVP (mm Hg) & $6.5 \pm 3.8$ & $0.6 \pm 0.5 \ddagger$ & $2.6 \pm 0.8 \dagger$ \\
\hline
\end{tabular}

Values are expressed as mean \pm SD. In exp A and C, bladderbox alarms are simulated by increase of the ECMO flow rate. In exp B, bladderbox alarms are simulated by partially clamping the venous cannula. All changes are compared with baseline values.

$* p<0.001$.

$\dagger p<0.01$.

$\$ p<0.05$.

NA, not available.

the period of bladderbox alarms as well, followed by a more acute decrease to values lower than baseline values after the bladderbox alarms were resolved.

Bladderbox alarms caused a significant and acute decrease in $\mathrm{HbD}, \mathrm{CBV}, \mathrm{MAP}$, and Qcar. There was a significant increase in CVP. During the $10 \mathrm{~s}$ course of bladderbox alarms, $\mathrm{HR}$ increased as did $\mathrm{HbD}, \mathrm{CBV}$, MAP, and Qcar; however, just before resolving the bladderbox alarms, values were still lower than preexperiment baseline values. Patterns for all parameters were not different between those bladderbox alarms simulated by increasing the ECMO flow rate and those simulated by partially clamping of the venous cannula. We did not find any significant difference between $\Delta \mathrm{HbD}_{\text {right }}$ and $\Delta \mathrm{HbD}_{\text {left }}$ or between $\Delta \mathrm{CBV}_{\text {right }}$ and $\Delta \mathrm{CBV}_{\text {left }}$. The decrease in $\mathrm{HbD}$ when simulating bladderbox alarms ranged from -0.05 to $-0.45 \mu \mathrm{mol} \cdot 100 \cdot \mathrm{g}^{-1}$, while the decrease in $\mathrm{CBV}$ ranged from 0 to $-0.20 \mathrm{~mL} \cdot 100 \mathrm{~g}^{-1}$.

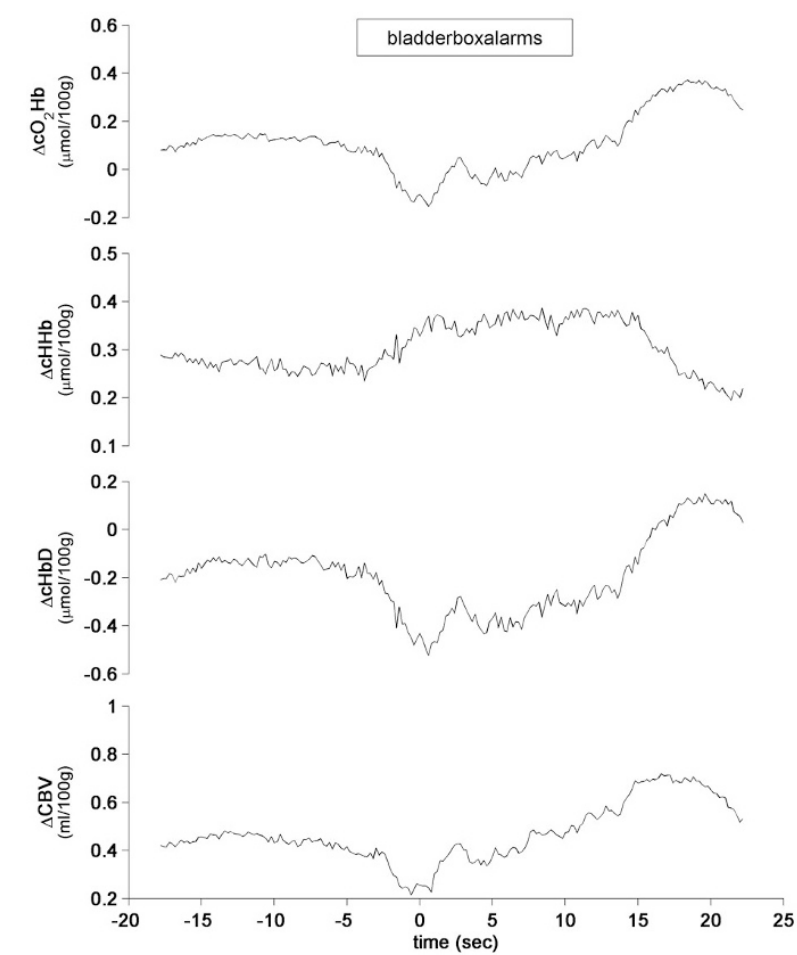

Figure 1. Typical pattern of changes in cerebral oxyhemoglobin $\left(\Delta \mathrm{cO}_{2} \mathrm{Hb}\right)$, deoxyhemoglobin $(\Delta \mathrm{cHHb}), \mathrm{Hb}$ oxygenation index $(\Delta \mathrm{HbD})$, and cerebral blood volume $(\Delta \mathrm{CBV})$ during and after bladderbox alarms.

When resolving the bladderbox alarms, there was a fast increase in $\mathrm{HbD}$ to values significantly higher than baseline values before the experiment. In experiment $C$, when bladderbox alarms were resolved by the administration of intravascular volume, this increase in $\mathrm{HbD}$ (range, 0.09 to 0.84 $\mu \mathrm{mol} \cdot 100 \cdot \mathrm{g}^{-1}$ ) was significantly larger than in experiments $\mathrm{A}$ and $\mathrm{B}$ [range, -0.06 to $0.35 \mu \mathrm{mol} \cdot 100 \cdot \mathrm{g}^{-1}(p<0.05)$ ]. Because normal saline is used as intravascular volume administration to resolve bladderbox alarms in experiment $\mathrm{C}$, this will result in hemodilution (decrease of $\mathrm{cHb}$ ). Therefore, changes in CBV cannot be reliably calculated. However, in experiments $\mathrm{A}$ and $\mathrm{B}, \mathrm{CBV}$ increased to values significantly higher than baseline values (range, 0 to $0.26 \mathrm{~mL} \cdot 100 \cdot \mathrm{g}^{-1}$ ). MAP and Qcar recovered to baseline values in experiments A and $\mathrm{B}$ but increased significantly when intravascular volume was administered (experiment C). CVP tends to decrease after bladderbox alarms are resolved but increases during intravascular volume administration. HR was still increased at the end of each experiment. Again, we did not find any significant difference between $\Delta \mathrm{HbD}_{\text {right }}$ and $\Delta \mathrm{HbD}_{\text {left }}$ or between $\Delta \mathrm{CBV}_{\text {right }}$ and $\Delta \mathrm{CBV}_{\text {left }}$.

\section{DISCUSSION}

Because cerebral hemorrhage and ischemia belong to the devastating complications of ECMO treatment, it is important to identify risk factors related to the use of the ECMO technique itself and eliminate these as much as possible. After describing a significant relation between intravascular volume administration during va-ECMO treatment and ICH (10), this is the first study to describe statistically significant 
changes in cerebral oxygenation and hemodynamics, expressed by $\triangle \mathrm{HbD}$ and $\triangle \mathrm{CBV}$, in relation to bladderbox alarms. These alarms often precede the need for intravascular volume administration.

Bladderbox alarms cause a stop of the ECMO pump, which results in an acute interruption of the arterial circulation and an acute decrease in MAP, Qcar, HbD, and CBV. Although bladderbox alarms persist, several mechanisms might explain observed findings of our study. First, in an attempt to restore the circulation, the body will try to increase cardiac output with an increase in HR. Especially, as lambs in our study have healthy lungs, an increase in cardiac output will result in an increased arterial blood flow, which explains the increase in MAP, Qcar, HbD, and CBV.

When the ECMO pump is interrupted, venous drainage from the right atrium will be reduced and CVP will increase resulting in less venous drainage from the brain. This might contribute to an increase in CBV. Finally, cerebral vasodilatation might occur as compensation for decreased CBF during bladderbox alarms. When bladderbox alarms are resolved, an acute recovery of ECMO flow will occur with a consecutive increase in MAP and Qcar, occurring while the system was just adapting to reduced CBF by vasodilatation. This might, partially, explain why there is an overshoot in $\mathrm{HbD}$ and $\mathrm{CBV}$ to values higher than baseline values. Once intravascular volume administration is used, there is a further increase of MAP, Qcar, and cerebral blood flow with a consecutive further increase in $\mathrm{HbD}$.

Several authors reported that the majority of cases of ICH occurred within $72 \mathrm{~h}$ after the start of ECMO (22-24). This might fit with our findings, as the majority of bladderbox alarms occur in the first days of ECMO treatment, when a relatively high ECMO flow rate is required to maintain adequate arterial oxygen saturation in a period that the patients lung is passing a phase of "white out" and the patient is still hemodynamically stabilizing. Next to this, the acute changes in $\mathrm{HbD}$ and $\mathrm{CBV}$, related to bladderbox alarms in the first days, occur while cerebral autoregulation (AR) in the patient seems to be disturbed. In normal, healthy infants, AR maintains the cerebral blood flow over a wide range of cerebral perfusion pressures with a contra-regulation response occurring with a delay of $2 \mathrm{~s}$ after sudden changes in blood pressure. However, it has been shown that AR is disturbed in severely ill term infants (25-28). Additional studies in newborn lambs showed that prolonged hypoxia and/or the ECMO treatment itself significantly disturbs the AR (29-32). These studies demonstrated that AR in lambs placed on ECMO was more disturbed in animals that had hypoxia before ECMO compared with animals without preceding hypoxia. Therefore, the hemodynamic changes that occur during bladderbox alarms as demonstrated in our study could even be more profound in the clinical situation of newborns with respiratory and/or circulatory distress.

Large prospective randomized studies in human newborns to investigate the relation between (simulated) bladderbox alarms and the occurrence rate of intracranial lesions during treatment with ECMO are impossible to perform. Therefore, it is important to establish observational intervention studies.
The most important limitation of using NIRS, with its variables like $\mathrm{HbD}$ and $\mathrm{CBV}$, is the lack of reference values below which global cerebral oxygenation and hemodynamics are compromised and clinically relevant for the individual patient. Findings can be used to describe trends in a group of patients and the relevance can only be suspected when compared with studies where known risk factors for the brain are related to changes in NIRS variables. Baseline variability of $\mathrm{HbD}$ has been described to range from -0.12 to +0.13 $\mu \mathrm{mol} \cdot 100 \cdot \mathrm{g}^{-1}(33)$. With a variability of $0.03 \pm 0.01$, this was lower in our study. In the same study, a decrease in $\mathrm{HbD}$ of $>0.3 \mu \mathrm{mol} \cdot 100 \cdot \mathrm{g}^{-1}$ is likely to be clinically relevant since this was found to correspond with the effect of reducing $\mathrm{SaO}_{2}$ by $\sim 12 \%$. Compared with these values, mean changes in $\mathrm{HbD}$ of 0.11 to $0.33 \mu \mathrm{mol} \cdot 100 \cdot \mathrm{g}^{-1}$ and changes for individual lambs in $\mathrm{HbD}$ up to $0.45 \mu \mathrm{mol} \cdot 100 \cdot \mathrm{g}^{-1}$ in experiments $\mathrm{A}$ and $\mathrm{B}$ and up to $0.84 \mu \mathrm{mol} \cdot 100 \cdot \mathrm{g}^{-1}$ when intravascular volume administration was used could be important. Fluctuation of $\mathrm{HbD}$, expressed as changes between maximal decrease in $\mathrm{HbD}$, and the consecutive maximal increase in $\mathrm{HbD}$ are even more profound. For $\triangle \mathrm{CBV}$, changes have been compared with usual physiologic parameters like changes in $\mathrm{PaCO}_{2}$ and MAP. During hypercapnia in normoxemic piglets on ECMO, a mean $\triangle \mathrm{CBV}$ of $0.03 \mathrm{~mL} \cdot 100 \cdot \mathrm{g}^{-1} \cdot \mathrm{kPa}^{-1}$ occurred (34). In another study, $\triangle \mathrm{CBV}$ was calculated in relation to changes in MAP in newborn lambs to be 0.07 $\mathrm{mL} \cdot 100 \mathrm{~g}^{-1} \cdot \mathrm{mmHg}^{-1}(35)$. Compared with these values, a mean change in $\mathrm{CBV}$ of 0.11 to $0.13 \mathrm{~mL} \cdot 100 \cdot \mathrm{g}^{-1}$ and changes for individual lambs in $\mathrm{CBV}$ up to 0.26 $\mathrm{mL} \cdot 100 \cdot \mathrm{g}^{-1}$ as found in our study could be important. Changes between the maximal decrease in CBV and consecutive maximal increase in CBV are more profound. Finally, the value of $\mathrm{CBV}$ in lambs has been found to be 2.5 $\mathrm{mL} \cdot 100 \cdot \mathrm{g}^{-1}$ (36). Changes in CBV found in our study are up to $10 \%$. Besides the magnitude, changes in $\mathrm{HbD}$ and $\mathrm{CBV}$ occur very acute, which might be an additional risk factor for cerebral lesions by itself. Some authors describe predominance of cerebral lesions in especially the right hemisphere of the brain, whereas in other studies, this predominance, possibly related to ligation of the right carotic artery and right internal jugular vein, could not be confirmed (37-43). To study differences between both hemispheres, we used two receiving NIRS optodes. However, changes in $\mathrm{HbD}$ and $\mathrm{CBV}$ were not different between the left and right hemisphere of the brain.

Cerebral hemorrhage and ischemia are generally considered to be caused by preECMO as well as ECMO-related factors. We showed a significant relation between bladderbox alarms and changes in cerebral oxygenation and hemodynamics. This might play a role in the development of neurologic sequelae. As changes in $\mathrm{HbD}$ and $\mathrm{CBV}$ are more extended when bladderbox alarms are resolved by administration of normal saline, it would be interesting to further study the effects on cerebral oxygenation and hemodynamics of intravascular volume administration by itself as well. The results of our study are limited to ECMO systems with a rollerpump and a bladderbox and might support the use of centrifugal pumps, systems without a bladderbox or ECMO strategies with re- 
duced bladderbox alarms. However, more research is needed for other systems as well to study, for example, the effects of less-controlled drainage from the right atrium of the patient and cerebral oxygenation and hemodynamics.

On the basis of this study, we conclude that bladderbox alarms during treatment with va-ECMO result in statistically significant fluctuations in cerebral oxygenation and hemodynamics. This might be an additional risk factor for the occurrence of intracranial hemorrhage and ischemia.

\section{REFERENCES}

1. Lequier L 2004 Extracorporeal life support in pediatric and neonatal critical care: a review. J Intensive Care Med 19:243-258

2. Rais-Bahrami K, Short BL 2000 The current status of neonatal extracorporeal membrane oxygenation. Semin Perinatol 24:406-417

3. Bartlett RH, Gazzaniga AB, Jefferies MR, Huxtable RF, Haiduc NJ, Fong SW 1976 Extracorporeal membrane oxygenation (ECMO) cardiopulmonary support in infancy. Trans Am Soc Artif Intern Organs 22:80-93

4. Extracorporeal Life Support Organization 2008 ELSO Registry Report 2008. Ann Arbor, MI

5. Short BL 2005 The effect of extracorporeal life support on the brain: a focus on ECMO. Semin Perinatol 29:45-50

6. Hofkosh D, Thompson AE, Nozza RJ, Kemp SS, Bowen A, Feldman HM 1991 Ten years of extracorporeal membrane oxygenation: neurodevelopmental outcome. Pediatrics 87:549-555

7. Lazar EL, Abramson SJ, Weinstein S, Stolar CJ 1994 Neuroimaging of brain injury in neonates treated with extracorporeal membrane oxygenation: lessons learned from serial examinations. J Pediatr Surg 29:186-190

8. Graziani LJ, Gringlas M, Baumgart S 1997 Cerebrovascular complications and neurodevelopmental sequelae of neonatal ECMO. Clin Perinatol 24:655-675

9. Bulas D, Glass P 2005 Neonatal ECMO: neuroimaging and neurodevelopmental outcome. Semin Perinatol 29:58-65

10. de Mol AC, Gerrits LC, van Heijst AF, Straatman H, van der Staak FH, Liem KD 2008 Intravascular volume administration: a contributing risk factor for intracranial hemorrhage during extracorporeal membrane oxygenation? Pediatrics 121:e1599e1603

11. van Heijst A, Liem D, van der Staak F, Klaessens J, Festen C, de Haan T, Geven W, van de Bor M 2001 Hemodynamic changes during opening of the bridge in venoarterial extracorporeal membrane oygenation. Pediatr Crit Care Med 2:265-270

12. van der Sluijs MC, Colier WN, Houston RF, Oeseburg B 1998 A new and highly sensitive continuous wave near infrared spectrophotometer with multiple detectors. Proc Soc Photo Opt Instrum Eng 3194:63-72

13. Jöbsis FF 1977 Noninvasive, infrared monitoring of cerebral and myocardial oxygen sufficiency and circulatory parameters. Science 198:1264-1267

14. Liem KD, Kollée LA, Klaessens JH, Geven WB, Festen C, de Haan AF, Oeseburg B 1995 Disturbance of cerebral oxygenation and hemodynamics related to the opening of the bypass bridge during veno-arterial extracorporeal membrane oxygenation. Pediatr Res 38:124-129

15. Liem KD, Hopman JC, Kollée LA, Oeseburg B 1994 Effects of repeated indomethacin admnistration on cerebral oxygenation and hemodynamics in preterm infants: combined near infrared spectrophotometry and Doppler ultrasound study. Eur J Pediatr 153:504-509

16. Wickramasinghe Y, Rolfe P 1993 Modified NIR coefficients taking into account the wavelength dependence of the optical pathlength. In: Bancroft J (ed) Newsletter EC Concerted Action Near Infrared Spectroscopy and Imaging of Biological Tissue. Stok on Trent, UK, Issue 2, p 5

17. Cooper CE, Elwell CE, Meek JH, Matcher SJ, Wyatt JS, Cope M, Delpy DT 1996 The noninvasive measurement of absolute cerebral deoxyhemoglobin concentration and mean optical path length in the neonatal brain by second derivative near infrared spectroscopy. Pediatr Res 39:32-38

18. Duncan A, Meek JH, Clemence M, Elwell CE, Fallon P, Tyszczuk L, Cope M, Delpy DT 1996 Measurement of cranial optical path length as a function of age using phase resolved near infrared spectroscopy. Pediatr Res 39:889-894
19. Nelson SR, Mantz ML, Maxwell JA 1971 Use of specific gravity in the measurement of cerebral edema. J Appl Physiol 30:268-271

20. Tsuji M, duPlessis A, Taylor G, Crocker R, Volpe JJ 1998 Near infrared spectroscopy detects cerebral ischemia during hypotension in piglets. Pediatr Res 44:591595

21. Lammertsma AA, Brooks DJ, Beaney RP, Turton DR, Kensett JM, Heather JD, Marshall J, Jones T 1984 In vivo measurement of regional cerebral haematocrit using positron emission tomography. J Cereb Blood Flow Metab 4:317-322

22. Taylor GA, Fitz CR, Miller MK, Garin DB, Catena LM, Short BL 1987 Intracranial abnormalities in infants treated with extracorporeal membrane oxygenation: imaging with US and CT. Radiology 165:675-678

23. De Sanctis JT, Bransom RT, Blickman JG 1996 Can clinical parameters help reliably predict the onset of acute intracranial hemorrhage in infants receiving extracorporeal membrane oxygenation? Radiology 199:429-432

24. Dela Cruz TV, Stewart DL, Winston SJ, Weatherman KS, Phelps JL, Mendoza JC 1997 Risk factors for intracranial hemorrhage in the extracorporeal membrane oxygenation patient. J Perinatol 17:18-23

25. Greisen G 2005 Autoregulation of cerebral blood flow in newborn babies. Early Hum Dev 81:423-428

26. Aaslid R, Lindegaard KF, Sorteberg W, Nornes H 1989 Cerebral autoregulation dynamics in humans. Stroke 20:45-52

27. Panerai RB, Kelsall AW, Rennie JM, Evans DH 1995 Cerebral autoregulation dynamics in premature newborns. Stroke 26:74-80

28. Kontos HA, Wei EP, Navari RM, Levasseur JE, Rosenblum WI, Patterson JL Jr 1978 Responses of cerebral arteries and arterioles to acute hypotension and hypertension. Am J Physiol 234:H371-H383

29. Boylan GB, Young K, Panerai RB, Rennie JM, Evans DH 2000 Dynamic Cerebral Autoregulation in Sick Newborn Infants. Pediatr Res 48:12-17

30. Tweed A, Cote J, Lou H, Gregory G, Wade J 1986 Impairment of cerebral blood flow autoregulation in the newborn lamb by hypoxia. Pediatr Res 20:516-519

31. Short BL, Walker LK, Traystman RJ 1994 Impaired cerebral autoregulation in the newborn lamb during recovery from severe, prolonged hypoxia, combined with carotid artery and jugular vein ligation. Crit Care Med 22:1262-1268

32. Ashwal S, Majcher JS, Longo L 1981 Patterns of fetal lamb regional cerebral blood flow during and after prolonged hypoxia: Studies during the posthypoxia recovery period. Am J Obstet Gynecol 139:365-372

33. Watkin SL, Spencer SA, Dimmock PW, Wickramasinghe YA, Rolfe PA 1999 Comparison of pulse oximetry and near infrared spectroscopy (NIRS) in the detection of hypoxaemia occurring with pauses in nasal airflow in neonates. J Clin Monit Comput 15:441-447

34. Liem KD, Kollee LA, Hopman JC, de Haan AF, Oeseburg B 1995 The influence of arterial carbon dioxide on cerebral oxygenation and haemodynamics during ECMO in normoxaemic and hypoxaemic piglets. Acta Anaesthesiol Scand Suppl 107:157164

35. Van Os S, Klaessens J, Hopman J, Liem D, van de Bor M 2006 Cerebral oxygen supply during hypotension in near-term lambs: a near-infrared spectroscopy study. Brain Dev 28:115-121

36. Barfield CP, Yu VY, Noma O, Kukita J, Cussen LJ, Oates A, Walker AM 1999 Cerebral blood volume measured using near-infrared spectroscopy and radiolabels in the immature lamb brain. Pediatr Res 46:50-56

37. Campbell LR, Bunyapen C, Holmes GL, Howell CG Jr, Kanto WP Jr 1988 Right common cartid artery ligation in extracorporeal membrane oxygenation. J Pediatr 113:110-113

38. Schumacher RE, Barks JD, Johnston MV, Donn SM, Scher MS, Roloff DW, Bartlett RH 1988 Right-sided brain lesions in infants following extracorporeal membrane oxygenation. Pediatrics 82:155-161

39. Taylor GA, Short BL, Fitz CR 1989 Imaging of cerebrovascular injury in infants treated with extracorporeal membrane oxygenation. J Pediatr 114:635-639

40. Mendoza JC, Shearer LL, Cook LN 1991 Lateralization of brain lesions following extracorporeal membrane oxygenation. Pediatrics 88:1004-1009

41. Hahn JS, Vaucher Y, Bejar R, Coen RW 1993 Electroencephalographic and neuroimaging findings in neonates undergoing extracorporeal membrane oxygenation. Neuropediatrics 24:19-24

42. Lago P, Rebsamen S, Clancy RR, Pinto-Martin J, Kessler A, Zimmerman R, Schmelling D, Bernbaum J, Gerdes M, D'Agostino JA 1995 MRI, MRA and neurodevelopmental outcome following neonatal ECMO. Pediatr Neurol 12:294304

43. Bulas DI, Taylor GA, O’Donnell RM, Short BL, Fitz CR, Vezina G 1996 Intracranial abnormalities in infants treated with extracorporeal membrane oxygenation: update on sonographic and CT findings. AJNR Am J Neuroradiol 17:287-294 